\title{
Electrochemical Micromachining of Square Holes in Stainless Steel in $\mathrm{H}_{2} \mathrm{SO}_{4}$
}

\author{
Gu Mingcheng ${ }^{1}$, Zeng Yongbin ${ }^{1,2, *}$, Meng Lingchao ${ }^{1}$ \\ ${ }^{1}$ College of Mechanical and Electrical Engineering, Nanjing University of Aeronautics and \\ Astronautics, Nanjing 210016, China \\ ${ }^{2}$ Jiangsu Key Laboratory of Precision and Micro-Manufacturing Technology, Nanjing 210016, China \\ *E-mail: binyz@ nuaa.edu.cn
}

doi: $10.20964 / 2019.01 .40$

Received: 2 September 2018 / Accepted: 27 October 2018 / Published: 30 November 2018

\begin{abstract}
A method for fabricating micro square holes with small corner radius is proposed, which could find applications in the aerospace and aviation industries. The machining process includes three steps: (i) the hole is first fabricated by electrochemical drilling; (ii) the square hole is then rough machined by electrochemical milling; and (iii) finally the hole is finished by electrochemical milling to reduce the corner radius. To improve the stability and quality of machining, double-pulsed electrochemical machining (ECM) was applied to remove electrolysis products adhering to the electrode. Using optimal parameters, square holes with a radius of $12 \mu \mathrm{m}$ and a width of $100 \mu \mathrm{m}$ were fabricated on 321 stainless steel with a thickness of $0.1 \mathrm{~mm}$.
\end{abstract}

Keywords: electrochemical drilling; electrochemical milling; double-pulsed ECM; square hole; small radius

\section{FULL TEXT}

(C) 2019 The Authors. Published by ESG (www.electrochemsci.org). This article is an open access article distributed under the terms and conditions of the Creative Commons Attribution license (http://creativecommons.org/licenses/by/4.0/). 